\title{
Writing a manuscript for publication: An action research study with allied health practitioners
}

\author{
D. Harvey ${ }^{1}$, R. Barker ${ }^{2}$ \& E. Tynan ${ }^{3}$
}

Introduction: Writing a manuscript for publication is a challenge for those health practitioners whose primary role is to provide clinical services. The aim of this study was to increase the capacity of allied health practitioners who are employed in a clinical setting to submit manuscripts for publication in peer-reviewed journals.

Methods: An action research study design was used to develop a "Writing for Publication" program for nine allied health practitioners who had not previously published a manuscript as lead author. Between May and November 2018, at a regional public hospital service, three 90-minute writing workshops were offered, which included manuscript plan and preparation guide, academic writing instruction, peer review and mentoring by experienced researchers. Data were collected using participant pre- and post-program surveys, post-workshop focus groups and facilitator reflections.

Results: All participants reported that their writing skills had improved. Enablers to completing a manuscript for publication included structured preparation, mentoring, training in academic writing skills, protected writing time and external accountability. Challenges included not knowing where or how to start, competing priorities and distractions within and outside of work hours, inadequate academic writing skills and loss of momentum. Two participants submitted their manuscripts for publication by the end of the study and a further manuscript was submitted by the time of writing.

Conclusions: Strategies to ensure publication of allied health practitioner research findings need to be integrated into project planning and monitoring processes embedded within a well-supported health service-wide research culture.

Keywords: allied health personnel; publishing; writing; manuscripts; research support

Cairns and Hinterland Hospital and Health Service, College of Healthcare Sciences, James Cook University, Queensland, Australia

College of Healthcare Sciences, James Cook University, Queensland, Australia

Graduate Research School, James Cook University, Queensland, Australia

\section{Correspondence}

Desley Harvey

Health Practitioner Research Fellow

Cairns and Hinterland Hospital and Health Service

Cairns, Queensland 4870

Australia

Telephone: +61 742269706

Email: desley.harvey@health.qld.gov.au 
WRITING A MANUSCRIPT FOR PUBLICATION

\section{Introduction}

Research conducted by health practitioners in clinical practice is an important source of evidence for practice. Publication of this research in peer-reviewed journals is key to ensuring findings are disseminated for translation into practice (Gagliardi et al., 2014). Since 2011, Queensland Health has invested in building the capacity of allied health practitioners in clinical practice to undertake research (Hulcombe et al., 2014). Although allied health research activity has increased (Wenke, Tynan et al., 2017), confidence in writing for publication (Lazzarini et al., 2013) and publication in peer-reviewed journals (Wenke, Ward et al., 2017) has not been commensurate with the increased activity (Wenke, Mickan, \& Bisset, 2017). Even health services with reportedly high levels of research capacity and culture have demonstrated relatively low publication rates (Wenke, Mickan, \& Bisset, 2017).

Writing for publication is a challenge for health practitioners working in clinical settings right across the health professions (Singh \& Mayer, 2014; Wenke, Ward et al., 2017; Yancey, 2016). Barriers to publication reportedly include lack of time due to clinical demands and lack of academic writing skills, coupled with an inability to persist in the face of these barriers (Harvey et al., 2013; Mickan et al., 2017; Yancey, 2016). Strategies to increase publication rates have included writing retreats over 1 or 2 days (Bullion \& Brower, 2017; Jackson, 2008), writing workshops (Kulage \& Larson, 2016), writing mentors (Kennedy, 2017) and peer reviewers (Geithner \& Pollastro, 2015). Evidence of the effectiveness of these strategies when applied once off or within an embedded program within a clinical or research environment is limited.

A survey of allied health practitioners in a Northern Australian public sector health service identified writing for publication as the research task for which they had the least experience and highest need for support (Harvey et al., 2013; Pighills et al., 2013). Some even reported avoiding research because they were not confident writers (Harvey et al., 2013). To encourage publication at the study site, strategies included a day or evening "Writing a Journal Article" workshop, individual mentoring and online resources and guides. In the same site, there had been 32 peer-reviewed publications by allied health practitioners since 2013, far fewer than the number of projects completed during the same period. Monitoring and accountability for publication as a research output had also been limited.

The aim of this study was to increase the capacity of allied health practitioners employed in a clinical setting to submit manuscripts for publication in peer-reviewed journals. The objectives were to develop allied health practitioners' skills and confidence in writing for publication, to identify context-specific barriers and enablers to allied health practitioners writing a manuscript for publication and to mentor study participants to submit a manuscript for publication. 
WRITING A MANUSCRIPT FOR PUBLICATION

\section{Methods}

The study site was a regional Northern Australian public sector health service, which employed approximately 580 allied health practitioners. An action research methodology using multiple methods to collect and interpret data (McNiff \& Whitehead, 2011) was chosen for the study. Action research is a systematic form of collaborative inquiry, which involves people changing their professional practice and learning how to improve it by studying the effect of the change (Kemmis \& McTaggart, 1988). Iterative cycles of planning, action, observation, reflection and then, in turn, revising the plan for the next cycle were used to adjust the program design in response to data collected. The study design incorporated analysis of individual participants' strengths and challenges associated with writing for publication, which enabled solutions to be created to address barriers undermining each individuals' ability to write for publication.

Ethics approval was granted by the Far North Queensland Ethics Committee (HREC/18/QCH/37).

Participation in the study was voluntary. Eligible participants were employees of the public sector health service who had completed or were conducting a quality improvement project or research study, had not previously been first author on a peerreviewed journal publication and who responded to an email invitation sent via allied health clinical directors. Eligible participants who contacted the researchers were given an information sheet and provided written consent to participate. Two full-time allied health researchers, who were not currently in clinical practice or clinical supervisors for any participants, led the research and facilitated the workshops. The two researchers were also active participants in the action research process.

Over an 8-month period, three 90-minute face-to-face writing workshops were facilitated by two researchers. To limit disruption to the working day, each workshop commenced at $8 \mathrm{am}$ and involved education on how to write for publication, individualised strengths-based problem-solving and 30 minutes for writing. Workshop content and follow-up tasks were designed in response to needs identified by participants in the previous cycle.

Data were collected using a pre- and post-program participant survey, three postworkshop participant focus groups and three post-workshop reflective discussions by the workshop facilitators. Surveys were used to gather input from program participants whose practices and actions were the intended focus of the study. Designed by the researchers, surveys included both quantitative (categorical, Likert-scale) and qualitative (free-text) questions. The pre-program survey comprised 13 questions regarding participants' level of clinical responsibility, research qualifications and experience and self-perceived capacity for writing for publication. The post-program survey comprised nine questions on workshop attendance, peer reviews completed, confidence in writing a manuscript for publication and usefulness of program activities, materials, content and facilitators. Focus groups facilitated by both researchers were used to gather participant reflections on program activities and progress towards their writing goals and to identify potential strategies to achieve change. Post-workshop reflective 
WRITING A MANUSCRIPT FOR PUBLICATION

discussions between workshop facilitators (DH and $\mathrm{RB}$ ) focused on the value of the workshop to participants, participant progress and challenges, and strategies to address challenges. Focus group and post-workshop reflective discussions were recorded on a digital recorder and transcribed for analysis.

\section{Data analysis}

To describe participant characteristics and experience, descriptive statistics were used to calculate means and proportions from pre-program survey data. Due to the small sample, responses to free-text questions were collated verbatim in an Excel spreadsheet. Pre- and post-program survey data were not linked. Focus group data were analysed using an inductive qualitative content analysis approach (Sandelowski, 2000), which is "low inference" (Sandelowski, 2000, p. 335) and useful when the intent is to derive a descriptive rather than a conceptual summary of patterns in the data. Both researchers read the focus group transcripts several times. One researcher $(\mathrm{DH})$ coded the data into a number of descriptive codes and grouped codes into subthemes, which were subsumed into a smaller number of themes supported by participants' quotations. The second researcher $(\mathrm{RB})$ reviewed the themes, subthemes and quotations. Differences were discussed and a final descriptive summary was agreed and collated in a matrix. The same process was used for post-workshop reflective discussions between workshop facilitators. The researchers met to discuss and reflect on the focus group analysis, identify learnings and plan the next cycle of activity. This process was repeated after each workshop.

\section{Results}

Participant characteristics and research topics are detailed in Table 1. Workshops were facilitated by two researchers (DH, RB), with support from a third researcher (ET), who provided instruction in academic writing skills in the second and third workshops. Seven participants attended three workshops, and two participants attended two workshops. Seven completed one peer review, and two completed two peer reviews of manuscripts. Between each workshop, participants and mentors made contact between one and five times, and on average twice. Two participants submitted their manuscript to their chosen journal within the study timeframe; both were enrolled in a research higher degree. A third participant submitted a manuscript for publication at the time of writing of this manuscript. Two manuscripts have now been published.

All nine participants completed the pre- and post-workshop survey, however one postworkshop survey was incomplete and was, therefore, excluded from the analysis. All participants present in each workshop contributed to part or all of the focus group interviews. The workshop facilitators provided reflections after all three workshops. Pre-program participant research experience and factors impacting capacity to write for publication are shown in Figure 1 and Table 2, respectively. The four action research cycles for the study are shown in Figure 2. Details of workshop content are shown in Table 3 and post-program participant satisfaction in Table 4. 


\section{WRITING A MANUSCRIPT FOR PUBLICATION}

\section{Table 1}

Participant $(n=9)$ Characteristics and Manuscript Topics

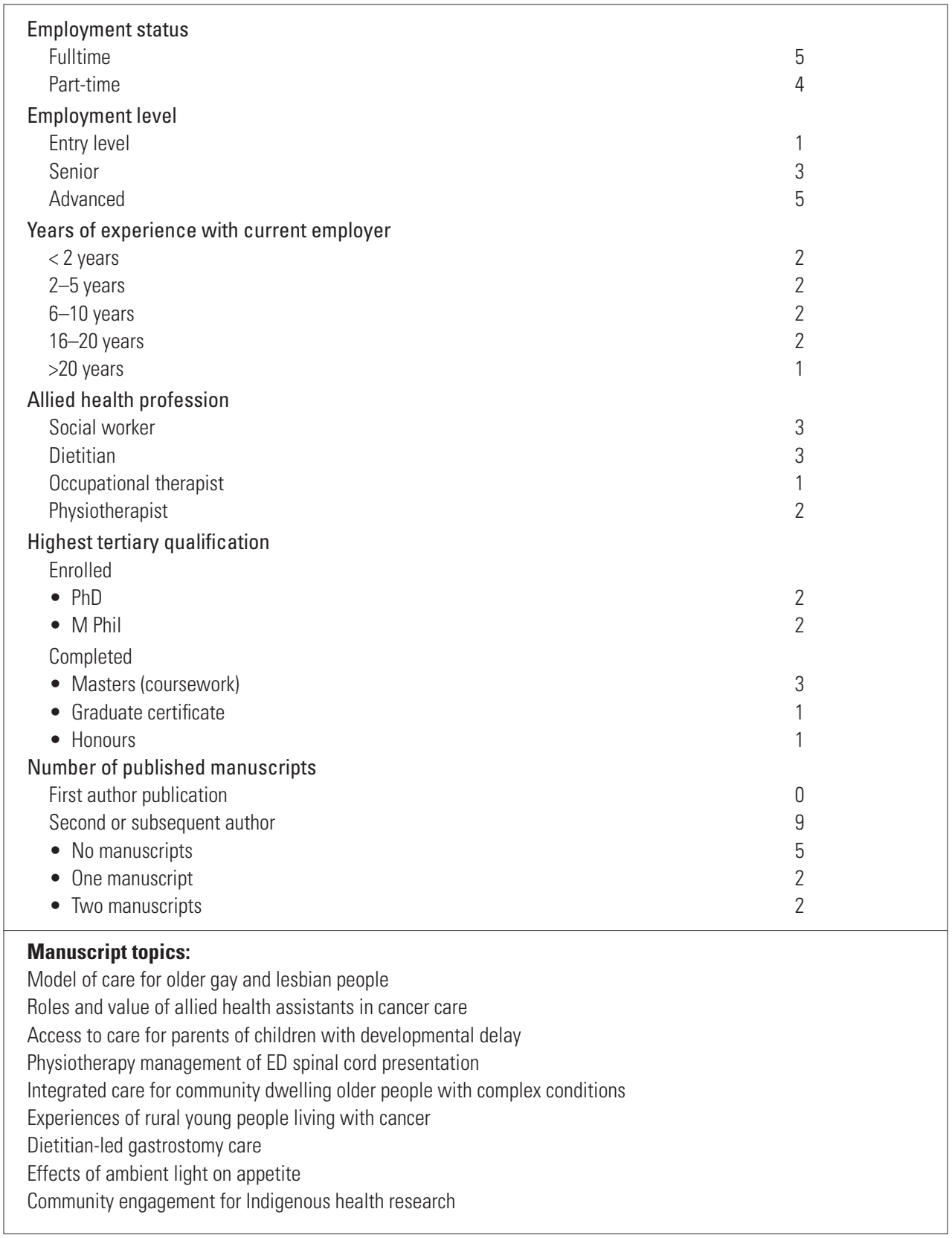


WRITING A MANUSCRIPT FOR PUBLICATION

\section{Table 2}

Participant Characteristics

\begin{tabular}{l|c|c|c}
\hline Question & $\begin{array}{c}\text { Average Score } \\
(1=\text { not at all, } \\
5=\text { completely })\end{array}$ & $\begin{array}{c}\text { Number of Participants } \\
\text { Who Scored } \\
\text { "Not at All" }\end{array}$ & $\begin{array}{c}\text { Number of Participants } \\
\text { Who Scored } \\
\text { "Completely" }\end{array}$ \\
\hline $\begin{array}{l}\text { I am able to prioritise } \\
\text { writing over other } \\
\text { activities }\end{array}$ & 2.8 & 0 & 0 \\
\hline $\begin{array}{l}\text { I am able to dedicate time } \\
\text { at work to write }\end{array}$ & 2.4 & 2 & 0 \\
\hline $\begin{array}{l}\text { I have the academic skills } \\
\text { to write }\end{array}$ & 3.5 & 0 & 0 \\
\hline $\begin{array}{l}\text { I have support from } \\
\text { management to write }\end{array}$ & 3.3 & 0 & 0 \\
\hline $\begin{array}{l}\text { I am confident that I can } \\
\text { write a manuscript suitable } \\
\text { for publication in a peer- } \\
\text { reviewed journal }\end{array}$ & 3.5 & & 0 \\
\hline $\begin{array}{l}\text { I know how to get started } \\
\text { I am able to make time } \\
\text { outside work to write }\end{array}$ & 2.2 & 3 & 2 \\
\hline $\begin{array}{l}\text { I know how to use Endnote } \\
\text { referencing software }\end{array}$ & 3.5 & 0 & 3 \\
\hline $\begin{array}{l}\text { I am able to find and } \\
\text { critically review the } \\
\text { literature }\end{array}$ & 3.4 & 2 & 0 \\
\hline
\end{tabular}

\section{Figure 1}

Pre-study Research Experience

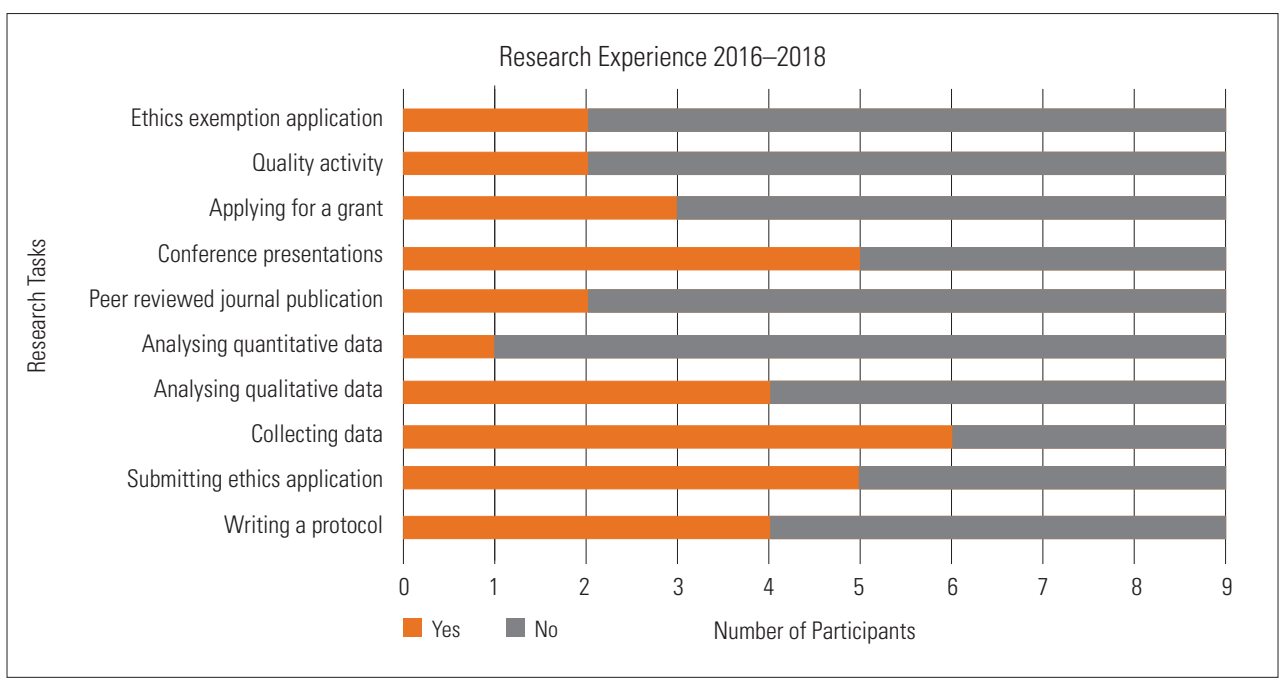




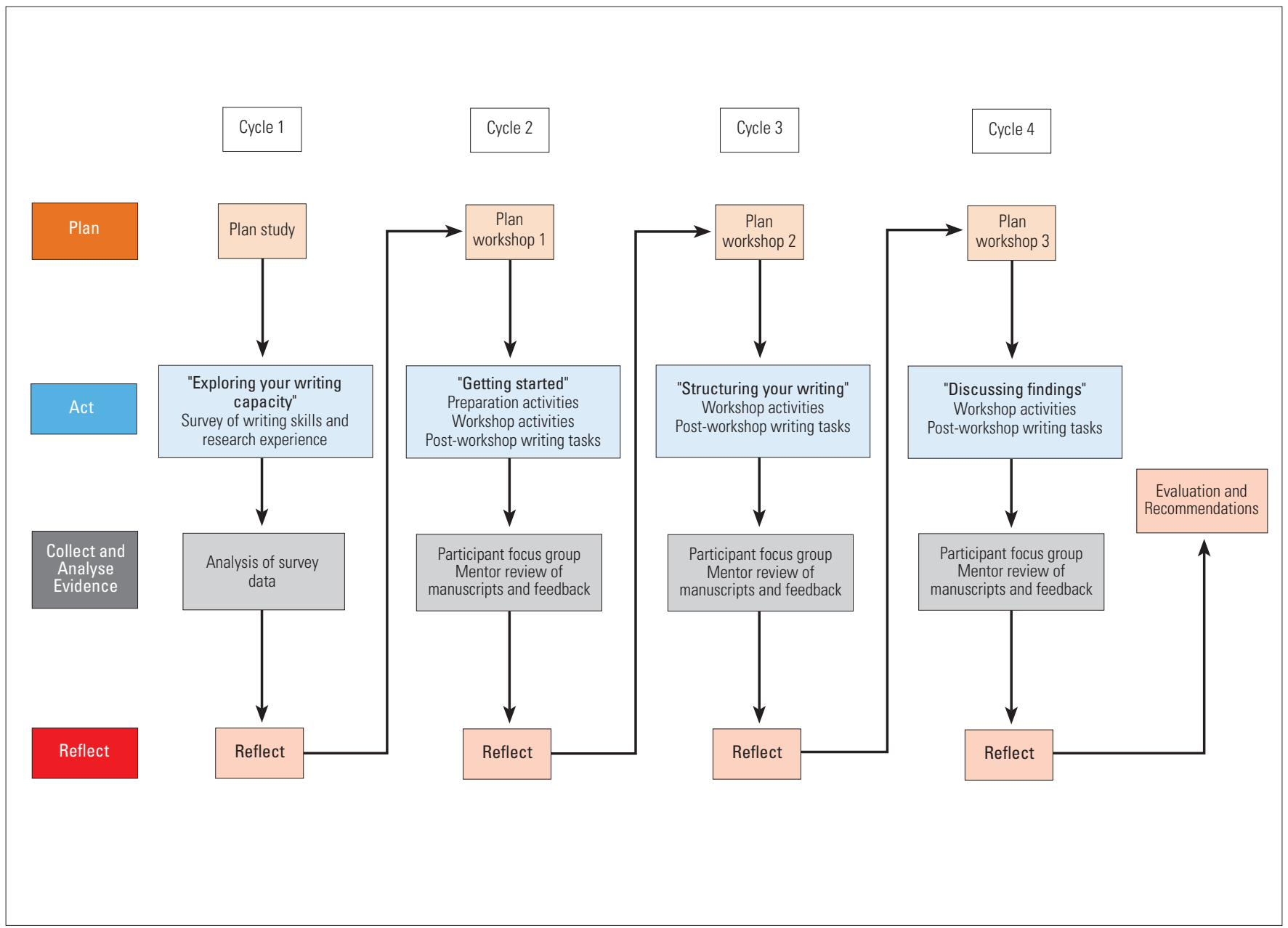




\section{WRITING A MANUSCRIPT FOR PUBLICATION}

\section{Table 3}

Program Structure and Content

\begin{tabular}{|c|c|c|}
\hline Program Content & Program Activity/Support & Tasks for Completion by Next Workshop \\
\hline Pre-workshop 1 & $\begin{array}{l}\text { Email to participants with Preparation } \\
\text { Checklist }\end{array}$ & $\begin{array}{l}\text { Laptop with Endnote, target journal and } \\
\text { example publication identified, author } \\
\text { guidelines, standardised reporting guidelines } \\
\text { for manuscript }\end{array}$ \\
\hline Workshop 1 & $\begin{array}{l}\text { - Introductions and learning outcomes } \\
\text { - Feedback results of pre-program survey } \\
\text { - Introduce Gantt chart and structure and } \\
\text { content template } \\
\text { - } 30 \text { minutes individual writing time } \\
\text { - Researcher/mentor allocated } \\
\text { - Post-workshop focus group }\end{array}$ & $\begin{array}{l}\text { Complete Gantt chart and structure and } \\
\text { content template } \\
\text { Write manuscript section as per individual } \\
\text { Gantt chart and submit to mentor for feedback }\end{array}$ \\
\hline Workshop 2 & $\begin{array}{l}\text { - Focus group analysis feedback to group, } \\
\text { reviews of Gantt chart, structure and } \\
\text { content template and manuscripts } \\
\text { - Presentation on constructing an argument } \\
\text { and paragraph and sentence structure } \\
\text { - } 90 \text { minutes writing time } \\
\text { - Post-workshop focus group }\end{array}$ & $\begin{array}{l}\text { Write next manuscript section as per Gantt } \\
\text { chart and submit to mentor for feedback; } \\
\text { revise and submit to coinvestigators; revise } \\
\text { and submit to mentor. Conduct a peer review } \\
\text { of at least one participant manuscript }\end{array}$ \\
\hline Workshop 3 & $\begin{array}{l}\text { - Focus group analysis feedback to group, } \\
\text { review of manuscripts, discussion about } \\
\text { peer review process } \\
\text { - Presentation on writing the discussion } \\
\text { - Activity in pairs on writing the discussion } \\
\text { - Individual activity ( } 15 \text { minutes) to complete } \\
\text { "Writing a Discussion" worksheet } \\
\text { - Presentation on the art of editing/concise } \\
\text { writing } \\
\text { - } 30 \text { minutes writing time } \\
\text { - Post-workshop focus group }\end{array}$ & $\begin{array}{l}\text { Write complete manuscript draft and email to } \\
\text { mentor for review } \\
\text { Complete post-program survey } \\
\text { Option of submitting further revisions for } \\
\text { feedback }\end{array}$ \\
\hline
\end{tabular}


WRITING A MANUSCRIPT FOR PUBLICATION

\section{Table 4}

Participant Satisfaction With "Writing for Publication" Program

\begin{tabular}{l|c|c|c}
\hline Question & $\begin{array}{c}\text { Average Score } \\
(1=\text { not at all, } \\
5=\text { completely) }\end{array}$ & $\begin{array}{c}\text { Number of Participants } \\
\text { Who Scored } \\
\text { "Not at All" }\end{array}$ & $\begin{array}{c}\text { Number of Participants } \\
\text { Who Scored } \\
\text { "Completely" }\end{array}$ \\
\hline $\begin{array}{l}\text { Confidence in ability to } \\
\text { write a manuscript for } \\
\text { publication }\end{array}$ & 3.8 & 0 & 1 \\
\hline $\begin{array}{l}\text { Confidence to conduct a } \\
\text { manuscript peer review }\end{array}$ & 3.3 & 0 & 0 \\
\hline $\begin{array}{l}\text { Resources useful } \\
\text { Writing mentors effective }\end{array}$ & 4.1 & 0 & 6 \\
\hline $\begin{array}{l}\text { Effective with respect to } \\
\text { project aims }\end{array}$ & 3.8 & 0 & 6 \\
\hline \begin{tabular}{l} 
Improved as a writer \\
\hline $\begin{array}{l}\text { Project was a valuable use } \\
\text { of my time }\end{array}$
\end{tabular} & 5 & 1 & 5 \\
\hline $\begin{array}{l}\text { Achieved personal } \\
\text { writing goals }\end{array}$ & 3.8 & 0 & 8 \\
\hline
\end{tabular}

\section{Action research cycle to build program structure and content}

Workshop structure and content (Table 3) were designed through:

- planning in response to the pre-program survey

- action before, during and after each workshop

- observation (data collection and analysis) during and between workshops

- reflection after workshops

- revising the plan (workshop and post-workshop activities) in readiness for the next action research cycle.

This enabled workshop content and activities to be designed in response to the needs of the participants rather than being pre-determined by the researchers. In Cycle 1, pre-program survey responses indicated that participants struggled with how to get started, how to structure a manuscript and how to write using research language instead of clinical or project language. Hence, Cycle 2 began with a plan for workshop one that included tasks before, during and after the workshop on "how to get started", including targeting a journal and manuscript format and content. After the workshop, post-workshop activities and review of writing submitted by participants, we identified that participants still struggled to develop an overall argument for their manuscripts. Participants also requested additional writing time at the end of the next workshop and an opportunity to learn by reviewing each other's writing. Therefore, Cycle 3 began with a plan for workshop two that included a 30-minute session from a researcher with expertise in teaching academic writing skills (ET). This session focused on constructing 
WRITING A MANUSCRIPT FOR PUBLICATION

an argument and structuring sentences and paragraphs. Participants also had the option of 90 minutes rather than 30 minutes individual writing time at the end of the workshop and were invited to peer review another manuscript before workshop three. After this workshop, the post-workshop activities and review of manuscripts submitted, it became clear that many participants had difficulty writing the discussion section of the manuscript and needed assistance with editing their work to adhere to the word length for their chosen journal. Therefore, the plan for Cycle 4 involved a third workshop that was focused on strategies and activities to assist with writing a discussion section and editing for a "final polish" of a manuscript. The expectation at the end of this final workshop was for participants to complete and submit their manuscripts.

\section{Participant and researcher reflections on program content and structure}

All participants reported that their writing skills improved and that the "Writing for Publication" program had been a valuable use of their time.

\section{Skills and confidence in writing for publication}

After the first workshop, most participants reported feeling confident about starting and continuing writing. Participants attributed this confidence to the preparation activity (identifying the journal and an example paper to model their writing on) and workshop activities (goal, plan, manuscript structure and content template).

Before, when I started doing this, it was more like I am lost; I don't really know where to start. ... You know, what sort of paragraph, what sort of information I need to put in certain sections. (FG1)

Learning how to write and how to engage the reader using appropriate research language were skills participants felt would enable them to be confident and competent in preparing a manuscript for publication. By the end of the second workshop, participants reported having a better understanding of scientific writing overall, including sentence and paragraph structure, as well as the need to persist with multiple drafts to achieve clarity of expression. Writing the discussion was the greatest challenge, with some participants not attempting to write the discussion section prior to the final workshop.

The discussion area ... that is such a difficult area to write, a little but more as to how we put that together might be useful. (FG2)

Understanding how to refine their manuscript was emerging as an issue by the third workshop. Participants recognised the value of feedback, both receiving and giving feedback in the form of peer review. They also understood that the writing and rewriting process was required to refine their argument.

I've further refined exactly what I want to happen in my article, so I had a few lightbulb moments with the feedback. (FG2) 
WRITING A MANUSCRIPT FOR PUBLICATION

\section{Enablers of writing for publication}

Preparation for writing was valued by participants. They particularly liked having a goal for publication, a plan for achieving their goal and a structure to follow, even those participants who had already begun drafting a manuscript.

Looking up the journal that you want to publish in ... investigating what they are looking for, having a look at articles that are similar to what you want to do ... that gives you a good guide. (FG1)

From the participants' perspective, set tasks between workshops provided structure and held them to account, which helped to maintain their momentum.

I've got some deadlines and some structures, which is really helpful because just out there before I was kind of just plodding along. (FG1)

Quarantined writing time to just sit down and write was highly valued. Following instruction on paragraph structure and writing a "discussion" in workshop two and three, respectively, participants felt motivated to write, as they were able to immediately apply what they had learnt. Writing time under the strict conditions imposed during the workshop (writing not talking, writing not reading) led to more writing. After the third workshop, participants felt their writing skills and confidence to achieve their goal had increased through commitment and persistence.

The workshops actually made me sit down and dedicate time to it, and work on it, and submit a manuscript. (FG3)

Feedback on manuscripts was appreciated, as participants felt it was conducted in a safe environment and by someone who could provide an objective review. This included feedback on their written work, feedback to other participants and through providing and receiving peer review of manuscripts.

My struggle is being methodical in how I incorporate feedback into my manuscript. ... It's a step-by-step process, and you can't rush it. (FG3)

\section{Barriers to writing for publication}

Being unprepared for writing meant that some participants were immediately behind and stayed behind because they had limited access to a laptop and did not have Endnote software loaded. Others were burdened with indecision about the type of article or journal they were targeting, leaving them unsure of where to start.

Come prepared. ... It's really underestimated how much you really need to. (FG1)

Lack of time to write and a quiet space in which to write, at work or home, was a barrier for some participants but not others. Those who felt they lacked a suitable space at work were unaware of a quiet space in the library at the study site. Competing priorities, at work and at home, were a constant struggle for most participants, particularly for those who felt their clinical workload was all-consuming. 
WRITING A MANUSCRIPT FOR PUBLICATION

Maybe it's just about saying no and just really honouring that time that I put aside. (FG2)

Distractions plagued some participants, many of whom recognised their role in allowing the distraction to occur and the need to prioritise writing time.

I do put that time aside and then I get easily led at times. (FG2)

Participants increasingly recognised that writing takes discipline and felt that the biggest improvements they could make were committing and sticking to their writing plans and sticking to their Gantt chart. More resources or workshops were not considered the answer and might in themselves be a distraction from the task of writing.

Feedback was challenging for many participants, even though they knew they needed guidance and that the process would improve their manuscript. Some were reluctant to change what they had spent so much time writing yet recognised that they needed to "let go and let it grow" (FG3). Chasing feedback from co-authors was tiresome for one participant, however she learnt to be persistent yet flexible when other authors were involved.

You get all this feedback, oh gosh, why am I doing this. ... But it is trying to say, "well, no, it's just going to make it better" and ... trying not to get too emotionally attached to what you have written. (FG2)

Loss of momentum occurred for many participants, with monthly deadlines requested to overcome this problem. Others floated the idea of a writing group between workshops to help maintain motivation and momentum and to learn skills from each other (e.g., Endnote).

It kind of spurs you on to write when everybody else is enthusiastic as well, so whether we get together for a couple of hours at some point. (FG21)

As this was the first manuscript for publication that participants had ever prepared, the researchers offered further mentorship after the final workshop, however uptake was minimal. It appeared that once accountability ceased, the program was considered to be over.

\section{Discussion}

The aim of this action research project was to increase the capacity of allied health practitioners employed in clinical settings to publish their research in peer-reviewed journals. Nine allied health practitioners participated in three 90-minute workshops, pre- and post-workshop activities and mentorship over an 8-month period. Surveys and focus groups with participants before and after each workshop guided program structure, content and process within each cycle of the action research process. All participants felt their time was very well spent and that their writing skills had improved. Two participants submitted their manuscripts for publication by the end of the 9-month study period, and one has submitted their research since completion of the study. 
Ideally, preparation for publication starts when writing a project proposal (Walshe, 2018). Despite having completed their chosen projects, participants in this study typically reported not knowing where to start or where to publish their work. Publication had apparently not been a priority during project planning, with resources not explicitly allocated for this purpose (e.g., laptop, backfill). Despite working in a relatively wellresourced and supportive research environment, many participants did not have ready access to a personal computer and a suitable environment in which to write.

Although information on scientific writing had been available from an online training program, direct instruction on writing skills and individual feedback on draft manuscripts was sought, well received and highly valued. Similar to previous reports, participants' limited awareness and uptake of local resources and supports (Matus et al., 2019) possibly reflected little understanding of publication as an essential research output. More broadly speaking, this could represent the generally low level research culture found in allied health (Mickan et al., 2017). Integrating publication into project plans as a deliverable and including a publication plan with allocation of time and resources may help to promote writing a manuscript as a priority rather than an afterthought.

Lack of time was perceived to be a major barrier to publication due to clinical and personal demands, within and outside working hours, and difficulty prioritising and managing time and being able to stay on task amid many possible distractions at home and at work. Protected time seemed an ideal solution and one shown to improve publication rates by allied health practitioners in a clinical setting in Australia (Wenke, Weir et al., 2018). Yet finding time and/or backfill in a busy clinical role posed a challenge in a regional setting where recruitment and retention is difficult (Wenke, Weir et al., 2018). Hence, creative ways of providing protected time may need to be developed.

Success in producing a draft manuscript was, in part, attributed to external accountability to the mentor and the timeline created by the impending workshop. When considering the success of other similar programs, it is possible that the environment and culture surrounding the participants was not as conducive to writing, without peers to read and talk through drafts and, perhaps, even to write with (Borkowski et al., 2016). Protected time to write for publication has been implemented in allied health departments where research capacity building is prioritised and resourced (Wenke, Weir et al., 2018). Writing time within work hours, working with co-authors and more regular (perhaps weekly) access to a mentor (Wenke, Weir et al., 2018) could provide ongoing support and external accountability.

Submission of a manuscript was achieved by three participants in the current study. Perhaps not surprisingly, those who submitted a manuscript had an allocation of work time for research and were completing a research higher degree. While the final workshop was geared towards discussion and refining the manuscript, workshops could have continued to allow submission by a larger number of participants and included topics relating to the submission process and handling responses to reviewers (Wenke, 
WRITING A MANUSCRIPT FOR PUBLICATION

Weir et al., 2018). Furthermore, the drive for publication could have been embedded in a reward system to foster a stronger culture of research (Matus et al., 2019) within an integrated whole of system approach.

\section{Strengths and limitations}

While the workshop content and activities are specific to this study and not transferable, the action research approach offered an effective process for responding to the contextspecific enablers and barriers experienced by the participants. The methods have been described in detail to enable researchers in other settings to consider applicability of the approach to other contexts. Participants were a relatively small, self-selected highly motivated group of allied health practitioners who had conducted projects in a real-world setting and had volunteered to participate. It is possible that allied health practitioners with less experience and less motivation or from different allied health professions may have responded differently. In addition, the high level of satisfaction and self-efficacy may have been a socially desirable rather than personal response by participants, particularly as the researchers who delivered the program also collected the data and, hence, could have influenced responses.

\section{Future direction}

Allied health practitioners are known to have low publication rates compared to their nursing and medical peers (Mickan et al., 2017). To increase publication rates, forward planning and strategies for external accountability are required. For new studies, this includes making publication plans a budget item in grant applications and part of project management processes and department key performance indicators and identifying opportunities for co-authorship and university/service partnerships. Training in scientific writing together with professional mentors, protected writing time through clinical backfill, flexibility or sharing of responsibilities and peer support are also recommended. Furthermore, incentives to submit a manuscript for publication and reporting of research outputs as part of workload might stimulate growth of a research culture.

\section{Conclusions}

Research conducted by allied health practitioners needs to be published to ensure that research evidence can be translated into practice. The action research approach used in this study provided a practical process for determining strategies required to boost "writing for publication" by allied health practitioners working in a unique regional clinical setting. Ideally, plans for publication of research findings need to be integrated into overall project planning and monitoring processes and embedded within a health service-wide research culture that is well supported.

\section{Funding and conflicts of interest statement}

This study was funded in part by a grant from the College of Healthcare Sciences, James Cook University. The authors have declared no conflicts of interest. 
WRITING A MANUSCRIPT FOR PUBLICATION

\section{Acknowledgements}

We would like to thank the participants for their time and valuable insights.

\section{References}

Borkowski, D., McKinstry, C., Cotchett, M., Williams, C., \& Haines, T. (2016). Research culture in allied health: A systematic review. Australian Journal of Primary Health, 22(4), 294-303. https://doi.org/10.1071/PY15122

Bullion, J., \& Brower, S. (2017). Enhancing the research and publication efforts of health sciences librarians via an academic writing retreat. Journal of the Medical Library Association, 105(4), 394-399. https://doi.org/10.5195/jmla.2017.320

Gagliardi, A. R., Webster, F., Perrier, L., Bell, M., \& Straus, S. (2014). Exploring mentorship as a strategy to build capacity for knowledge translation research and practice: A scoping systematic review. Implementation Science, 9(1), 122. https:// doi.org/10.1186/s13012-014-0122-z

Geithner, C., \& Pollastro, A. (2015). Constructing engaged learning in scientific writing: Implementation and assessment of a blended pedagogical approach. Journal of Applied Research in Higher Education, 7(2), 292-307. https://doi. org/10.1108/JARHE-04-2014-0053

Harvey, D., Plummer, D., Pighills, A., \& Pain, T. (2013). Practitioner research capacity: A survey of social workers in northern Queensland. Australian Social Work, 66(4), 540-554. https://doi.org/10.1080/0312407X.2012.754916

Hulcombe, J., Sturgess, J., Souvlis, T., \& Fitzgerald, C. (2014). An approach to building research capacity for health practitioners in a public health environment: An organisational perspective. Australian Health Review, 38(3), 252-258. https:// doi.org/10.1071/AH13066

Jackson, D. (2008). Mentored residential writing retreats: A leadership strategy to develop skills and generic outcomes in writing for publication. Nurse Education Today, 29(1), 9-15. https://doi.org/10.1016/j.nedt.2008.05.018

Kennedy, A. (2017). Journal aspirations: Improving scientific writing and publication through a writing mentorship program. International Journal of Therapeutic Massage and Bodywork, 10(2), 1-2. https://doi.org/10.3822/ijtmb.v10i2.369

Kemmis, S., \& McTaggart, R. (1988). The action research planner (3rd ed.). Deakin University Press.

Kulage, K. M., \& Larson, E. L. (2016). Implementation and outcomes of a facultybased, peer review manuscript writing workshop. Journal of Professional Nursing, 32(4), 262-270. https://doi.org/10.1016/j.profnurs.2016.01.008

Lazzarini, P. A., Geraghty, J., Kinnear, E. M., Butterworth, M., \& Ward, D. (2013). Research capacity and culture in podiatry: Early observations within Queensland Health. Journal of Foot and Ankle Research, 6, Article 1. https://doi. org/10.1186/1757-1146-6-1 
WRITING A MANUSCRIPT FOR PUBLICATION

Matus, J., Wenke, R., Hughes, I., \& Mickan, S. (2019). Evaluation of the research capacity and culture of alllied health practitioners in a large public health service. Journal of Multidisciplinary Healthcare, 12, 83-96. https://doi.org/10.2147/ JMDH.S178696

McNiff, J., \& Whitehead, J. (2011). All you need to know about action research (2nd ed.). Sage.

Mickan, S., Wenke, R., Weir, K., Bialocerkowski, A., \& Noble, C. (2017). Strategies for research engagement of clinicians in allied health (STRETCH): A mixed methods research protocol. BMJ Open, 7(9), e014876. https://doi.org/10.1136/ bmjopen-2016-014876

Pighills, A., Plummer, D., Harvey, D., \& Pain, T. (2013). Positioning occupational therapy as a discipline on the research continuum: Results of a cross-sectional survey of research experience. Australian Occupational Therapy Journal, 60(4), 241-251. https://doi.org/10.1111/1440-1630.12057

Sandelowski, M. (2000). Whatever happended to qualitative description. Research in Nursing and Health, 23(4), 334-340. https://doi.org/10.1002/1098240X(200008)23:4<334::AID-NUR9>3.0.CO;2-G

Singh, V., \& Mayer, P. (2014). Scientific writing: Strategies and tools for students and advisors. Biochemistry and Molecular Biology Education, 42(5), 405-413. https:// doi.org/10.1002/bmb.20815

Walshe, C. (2018). Clear, simple, precise, meaningful: A quick guide to writing for publication. Indian Journal of Palliative Care, 24(4), 391-392. https://doi. org/10.4103/IJPC.IJPC_175_18

Wenke, R., Mickan, S., \& Bisset, L. (2017). A cross sectional observational study of research activity of allied health teams: Is there a link with self-reported success, motivators and barriers to undertaking research? BMC Health Services Research, 17(1), Article 114. https://doi.org/10.1186/s12913-017-1996-7

Wenke, R., Tynan, A., Scott, A., \& Mickan, S. (2018). Effects and mechanisms of an allied health research position in a Queensland regional and rural health service: A descriptive case study. Australian Health Review, 42(6), 667-675. https://doi. org/10.1071/AH17086

Wenke, R., Ward, E., Hickman, I., Hulcombe, J., Phillips, R., \& Mickan, S. (2017). Allied health research positions: A qualitative evaluation of their impact. Health Research Policy and Systems, 15(1), Article 6. https://doi.org/10.1186/s12961-0160166-4

Wenke, R., Weir, K., Noble, C., Mahoney, J., \& Mickan, S. (2018). Not enough time for research? Use of supported funding to promote allied health research activity. Journal of Multidisciplinary Healthcare, 11, 269-277. https://doi.org/10.2147/ JMDH.S157034

Yancey, N. R. (2016). The challenge of writing for publication: Implications for teaching-learning nursing. Nursing Science Quarterly, 29(4), 277-282. https://doi. org/10.1177/0894318416662931 